\title{
As audiências públicas no processo constituinte de 1987-88
}

Mariele Troiano

\section{Mariele Troiano}

Professora Adjunta na Universidade Federal Fluminense.

Email: troianomariele@gmail.com

Lattes: http://lattes.cnpq.br/3227437575714593

ORCID: https://orcid.org/0000-0002-1543-1327

\begin{abstract}
Resumo
Este artigo tem como proposta apresentar uma reflexão sobre como um determinado arranjo institucional foi desenhado, ainda no processo constituinte de 1987-88, e como seu desempenho, tal como proposto, pode ajudar no fortalecimento das instituições, não só tornando-as mais consolidadas, mas também propagando os valores democráticos em nossa sociedade. Assim, analiso o surgimento das comissões e das audiências públicas como um dos múltiplos eixos de atuação política que se desenhou a partir da Constituinte. Por meio de uma análise de conteúdo de atas e notas taquigráficas, conclui-se que, nesse período, iniciou-se um projeto democrático em nosso país pautado no acesso às arenas decisórias e participações em plenário.
\end{abstract}

\section{Palavras- chave}

Democracia. Legislativo. Comissões. Audiências Públicas.

\begin{abstract}
This paper aims to present a reflection on how a particular institutional arrangement was designed during the 1987-88 constitutional process and how its performance, as proposed, can help in the strengthening of institutions, not only making them more consolidated, but also propagating democratic values in our society. Thus, I analyse the emergence of commissions and public hearings as one of the multiple axes of political action drawn from the Constituent Assembly. Through a content analysis of minutes and shorthand notes, it is concluded that, in this period, a democratic project started in our country, guided by the access to the decision-making arenas and plenary attendance.
\end{abstract}

\section{Keywords}

Democracy. Legislative Power. Commissions. Public Hearings. 
Mariele Troiano

\section{Introdução}

Os estudos sobre instituições políticas no Brasil tiveram seu processo de consolidação iniciado em meados da década de 1980, e há algumas razões para isso ter acontecido nesse período. A primeira delas é uma das mais consensuais entre os cientistas políticos, por estar diretamente relacionada ao rearranjo institucional provocado pela Constituição de 1988. Afinal, o processo de redemocratização, embora com pontuais continuidades, configurou uma ruptura institucional em seu sentido pleno.

A segunda razão está relacionada a uma necessidade de responder às análises pessimistas que rondavam a nova engenharia institucional. Estudos esses liderados, em sua maioria, por pesquisadores internacionais que ecoavam incansavelmente que a ideia de um presidencialismo combinado com um sistema multipartidário seria ineficiente. A equação apresentada por autores renomados como Linz (1994) e Ames (2001) mostrava-se simples: o eleitorado que elege o presidente não é o mesmo que elege os parlamentares, logo, o funcionamento da nova democracia estaria fadada ao fracasso. Muitas vezes, esses estudos acabaram negligenciando, em suas explicações, o poder das coalizões. A partir disso, um conjunto de autores passou a discutir questões de conflito e cooperação entre os poderes até concluírem que o suposto fracasso, que embora tratado como peculiaridade do governo Collor, não teria sua causalidade diretamente atribuída ao arranjo das instituições brasileiras. Afinal, a pesquisa dos autores Cheibub, Przeworski e Saeigh (2004) provou que um governo de minorias pode ser tão efetivo quanto um governo de maiorias.

Com essa perspectiva de entender o arranjo institucional brasileiro pós-88, os estudos sobre instituições se multiplicaram e auxiliaram diretamente a consolidação da Ciência Política no Brasil, ganhando espaços antes tomados por economistas e suas interpretações focadas na rational choice e por comportamentalistas que canalizavam as explicações nas ações e comportamentos dos indivíduos. Ao longo desses anos, os institucionalistas se debruçaram, incansavelmente, para entender as prerrogativas do Executivo, os limites do Judiciário e a potência da atuação do Legislativo na configuração do sistema. É consensual que os trabalhos de Fernando Limongi e Argelina Figueiredo (1995; 1999) foram fundamentais para a comprovação do aumento do poder legislativo do presidente da República, mas, ao mesmo tempo, para os novos mecanismos de controle da ação parlamentar postos à disposição das lideranças partidárias. Ou seja, mostraram que, após 1988, a democracia brasileira seria desenhada minimamente por um Executivo forte e um Legislativo com partidos disciplinados.

Ao longo desses anos, o clássico mote "as instituições importam" foi superado em múltiplas reflexões e grupos de trabalhos de congressos nacionais e internacionais, atualizando as discussões. A literatura avançou ao concluir que democracias atuais morrem diferentemente de democracias consolidadas (LEVITSKY e ZIBLATT, 2018), que o presidencialismo de coalizão não é a particularidade institucional brasileira (RAILE, PEREIRA e POWER, 2011) e que vivenciamos uma onda reversa de democratização na América nas últimas décadas (MULLER, 2011). Rezende (2012) concluiu em seu trabalho a necessidade de aspectos subjetivos serem acrescentados nas teorias institucionalistas preocupadas com a gênese, o desenvolvimento e a mudança das instituições provocadas por causas exógenas. Nesse mesmo trabalho, o autor apresenta possíveis novas abordagens que fariam parte dessa indispensável atualização da literatura, estando entre elas os estudos interacionistas, ao propor um redimensionamento para as questões de agência. 
Para o caso brasileiro, a elasticidade e os limites institucionais democráticos parecem ser colocados à prova, de forma mais intensa, nos últimos anos. Após os movimentos do segundo semestre de 2013, o Brasil seguiu para a maior operação de combate à corrupção da história do país, a Lava-Jato. Os anos seguintes foram marcados pelo impeachment da então presidente Dilma Rousseff. Por fim, houve a eleição de um candidato que desde seu programa de governo se posicionava antissistêmico. Logo, mais que afirmar que as instituições funcionam no Brasil, os analistas têm se esforçado nos últimos anos para entender o que torna as instituições tão vulneráveis e o que as faz robustas.

Para Nogueira (2014), o país vive recentemente um mal estar institucional que antecede uma crise na representação. Ou seja, não se trata de uma dificuldade de os poderes da República cumprirem suas funções estratégicas na sociedade contemporânea, mas de uma fase profunda de transformação política que provoca um desgaste das instituições, a ponto de elas não responderem às expectativas com as quais foram criadas.

Segundo Shugart e Carey (1992), as legislaturas são, por definição constitucional, as principais instituições de formulação de políticas nas democracias modernas. Os autores afirmam que políticas das mais diversas naturezas (orçamentos, acordos, tratados etc.), de diferentes amplitudes (individuais ou coletivas) e, até mesmo, os direitos, em democracias, devem ser aprovados por legislaturas. Assim, o Poder Legislativo poderia ser definido por sua atuação de a) representar a diversidade; b) deliberar; c) cultivar informação e especialização; d) executar o poder decisório e e) controlar a maioria e o Poder Executivo (SHUGART e CAREY, 1992).

O objetivo deste trabalho é apresentar a proposta das audiências públicas nas comissões, estabelecida durante o processo constituinte de 1987-88, como parte de um projeto democrático em nosso país.

Para isso, volta-se ao processo constituinte como um marco de um projeto institucional. Apesar do grande número de estudos e da acessibilidade às informações sobre a Constituição de 1988, há ainda uma agenda de pesquisa a ser explorada sobre o funcionamento do processo constituinte na determinação do vigente processo decisório. Esse esforço torna-se mais que um compilado de memórias ao mostrar-se necessário para o entendimento de que a institucionalização do sistema democrático depende, também, do funcionamento das atribuições do Legislativo, ou seja, do trabalho em comissões, e do funcionamento das audiências públicas por meio da intersecção de interesses que esses espaços possibilitam.

Com essa finalidade, o artigo está dividido em quatro seções. Para além dessa introdução, a seção seguinte tem como objetivo apresentar o desenho das comissões, enquanto a terceira parte do artigo trata da dinâmica das audiências públicas. Ambas as seções são colocadas como exemplos de permeabilidade da sociedade e de controle do Legislativo. Por fim, há uma conclusão ressaltando a importância do desenho constitucional para que as instituições não só funcionem, mas também tornem o projeto o mais democrático possível.

\section{O trabalho das Comissões Temáticas}

O processo constituinte de $1987-88$ representou mais que um interregno de confecção da nossa atual Carta Magna, mas também um momento em que foi estruturado um conjunto de políticas e práticas que envolvia a prestação de contas referente a um passado recente, caracterizado por mazelas sociais, ao mesmo tempo em que demarcaria um projeto futuro de políticas consideradas mais igualitárias e inclusivas para o país. Discutir 
esse período é entender a importância e o funcionamento das nossas instituições democráticas.

O trabalho dividido em comissões no processo decisório teve início durante a Constituinte de 1987-88, visando responder a quatro principais demandas. A primeira, e talvez a mais importante de todas, é que ele visava suprir a atribuição de mais funcionalidade e dinamicidade ao fluxo de leis. Principalmente quando comparado a um único órgão produtor de lei, que poderia ser ainda mais lento e superficial (LEMOS, 2006: 157). A segunda consistia na divisão de tarefas. Essa especialização traria maior estabilidade para o jogo político ao apresentar uma engenharia coordenada entre os poderes da República, bem como um poder de fiscalização do Legislativo (ARROW, 1963). O terceiro motivo do surgimento das Comissões pautava-se em transformar o poder legislativo em uma arena permeável e adaptada para recepcionar as exigências sociais, reflexo da diversificação e do aumento da complexidade social. Por último, as comissões apresentavam, para além do voto, outras formas de demonstração de poder, como a negociação, ou seja, a possibilidade de construir consensos em um espaço de conflito de interesses.

Eduardo Noronha (2010) afirmou ser possível analisar o processo constituinte sob três perspectivas - exógena, endógena e intermediária - podendo levar às distintas e complementares interpretações do processo. Aqui, a análise exógena dá-se pelo entendimento do processo a partir de seus eventos externos. Um exemplo é o trabalho de Alberto Tosi Rodrigues (1993), com a dissertação Mobilização e conflito político: a campanha das Diretas-Já, que objetiva entender o movimento popular que exigia a volta do sistema democrático no início da década de 1980. Fatores exógenos costumam ser mais explícitos em análises históricas e tendem a lidar, de certo modo, com o inesperado durante o processo.

Já as análises endógenas da Constituinte consideram as implicações de dentro da arena decisória, tais como as regras procedimentais ou as atuações dos parlamentares, partidos políticos, líderes partidários, relatores e presidentes. Exemplos para esse tipo de abordagem são os trabalhos de Coelho (1999), Lopes (2008) e Pilatti (2008). Coelho (1999) examina a atuação coesa dos partidos políticos em momentos decisórios do processo, como a formação do grupo suprapartidário "Centrão". A ênfase dada por Lopes (2008) está na interação entre regras e atores, especificamente no poder de negociação dos membros do Partido do Movimento Democrático Brasileiro (PMDB) na ocupação das funções de relatorias e presidências. Apesar das divergências nas formas como cada autor conduziu suas análises, ressalto a convergência entre eles ao apontarem para a relevância do período constituinte e as raras menções aos períodos antecedentes e posteriores à Assembleia Nacional Constituinte (ANC).

Na abordagem de Pilatti (2008), a ênfase é dada aos mecanismos regimentais durante a formulação da Constituição, e como estes interferiram nas decisões a ponto de uma maioria partidária não ser suficiente para a produção do texto constitucional. Ou seja, mesmo com uma maioria conservadora proveniente das eleições ordinárias ocorridas em 1986, onde 201 pertenciam a partidos conservadores (PDS, PFL, PL, PDC, PTB), 306 pertenciam ao PMDB e apenas 50 a partidos de esquerda (PCB, PC do B, PDT, PSB e PT), os constituintes construíram um texto voltado muito mais para a transformação do que para a conservação. Uma das contribuições da obra está na ênfase à disposição dos constituintes nas comissões, apontando para a importância dos líderes partidários e relatores, por exemplo. 
Outra possibilidade de abordagem do processo constituinte é a intermediária, que combina os dois focos interpretativos anteriores, promovendo uma avaliação mais holística do processo. Nesse enfoque, para analisar os procedimentos é necessário considerar a atuação dos atores internos e externos, bem como o funcionamento das instituições (NORONHA, 2000). O exemplo mais notório dessa abordagem está na dissertação de mestrado de Lucas Brandão (2011), que apresenta como os instrumentos de participação popular, assegurados pelo Regimento Interno da ANC, provocaram a institucionalização de mecanismos de interação entre os parlamentares e os atores externos, ao mesmo tempo em que essa nova dinâmica político-legislativa influenciou a mobilização social e as atuações dos constituintes.

O mesmo enfoque está na obra de Backes, Azevedo e Araújo (2009) e, mais especificamente, na introdução de autoria do ex-parlamentar João Gilberto Lucas Coelho. Nessa obra, o processo constituinte é apresentado como fenômeno sociológico e político ao interpretarem as audiências públicas como inclusão de novos comportamentos políticos, bem como de uma agenda política. É essa abordagem que considero necessária para compreender o desenho das comissões e das audiências públicas para a consolidação do projeto democrático iniciado nesse período.

Há um conjunto de fatores que marcam o início da Constituinte enquanto um projeto democrático, incluindo os intensos movimentos organizados pela Central Única dos Trabalhadores (CUT), por empresários e por membros da Conferência Nacional dos Bispos do Brasil (CNBB). Admite-se que o lançamento da primeira Carta pela Constituinte aconteceu em 1971, no encontro nacional do partido Movimento Democrático Brasileiro (MDB), e que foi fortalecido pela campanha da Ordem dos Advogados do Brasil (OAB), encabeçada pelo então presidente Raymundo Faoro. Nota-se que o caminho entre os primeiros movimentos até a apresentação pública de um projeto de uma nova Constituição por Tancredo Neves (então candidato à Presidência da República pelo PMDB) durou cerca de 14 anos.

Tancredo Neves pode ser considerado o primeiro a idealizar, e também organizar, uma Comissão especializada no processo. Ele a chamou de Comissão Provisória de Estudos Constitucionais, e foi composta por 50 membros, que ficaram conhecidos como "os notáveis"1. Os notáveis teriam a tarefa de desenvolver estudos e pesquisas de interesse geral da Nação, sob o comando do jurista Afonso Arinos de Melo Franco². Por fim, esse mesmo grupo foi chamado de Comissão Afonso Arinos.

A Comissão Afonso Arinos existiu e durou de julho de 1985 a setembro de 1986. O resultado desse trabalho é polêmico na literatura especializada, pois quando se findou o relatório de atividades e este foi entregue ao então vice-presidente José Sarney (que havia assumido o poder após a morte de Tancredo Neves), ele foi arquivado. Mas a contradição existe no ponto em que, embora o texto produzido pela Comissão Afonso Arinos tenha sido bastante criticado pelos constituintes, ele era retomado em todos os momentos em que o trabalho na Constituinte precisava de auxílio para sua continuação (JOBIM, 1994). De qualquer modo, a preocupação do descarte de um texto previamente elaborado por 50 membros escolhidos por Tancredo é uma questão importante quando se trata de um projeto político democrático.

A instalação da Assembleia Nacional Constituinte (ANC) aconteceu no dia 2 de fevereiro de 1987, e foi com a Segunda Resolução do Regimento Interno que se desenhou o funcionamento das comissões, ou seja, o trabalho de confecção de leis por meio da divisão de tarefas conforme interesses e especialidades dos parlamentares. Esse documento definiu 
Mariele Troiano

que o trabalho fosse dividido em 24 subcomissões que entregariam, a posteriori, seus relatórios para oito comissões temáticas, e, por fim, estas desembocariam em uma única Comissão de Sistematização. Só assim as decisões seriam submetidas a duas rodadas de votações nominais em plenário.

Cada subcomissão e comissão contava com um presidente, dois vice-presidentes e um relator. As subcomissões foram compostas por 21 membros e as comissões por 63 membros, todos indicados pelos líderes partidários e de acordo com a proporcionalidade dos partidos políticos. A Comissão de Sistematização foi composta por 93 membros, entre eles os presidentes e relatores das comissões e das subcomissões. Logo, contabilizavam 559 membros, sendo 72 senadores (sendo 23 deles remanescentes do Regime Militar, rotulados como "senadores biônicos"3") e 487 deputados (SOUZA, 2001: 515). Aqui, há um contraponto a ser destacado: a passagem dos deputados e senadores para a condição de constituintes muito reflete o projeto democrático em construção, a importância dos interesses dos atores em jogo, bem como a transição qualificada em lenta e gradual. Bonavides (2000) justifica assim a escolha por uma Assembleia Derivada ao invés de Originária, que só se encontraria para a confecção da Carta e, com sua promulgação, seria dissolvida.

Foi na "Comissão de Organização dos Poderes e Sistema de Governo", especificamente na "Subcomissão do Legislativo", que as funções legislativas foram definidas, embora a discussão sobre a estrutura do presidencialismo permeasse os debates de inúmeras comissões.

Limongi (1994) aponta que o propósito dos parlamentares envolvidos nessa subcomissão era em prol do fortalecimento da função legislativa, tanto do Executivo quanto do Legislativo, visando tornar o processo decisório mais ágil e eficiente, principalmente quanto à aprovação de leis. Com esse objetivo, foi assegurado o poder conclusivo (terminativo) às comissões, bem como foram sustentadas as prerrogativas legislativas do Executivo via Medidas Provisórias (MPs).

Embora uma medida provisória seja de uso exclusivo do presidente da República e mesmo possuindo um caráter de tramitação urgente no Congresso Nacional, definiu-se por meio de uma emenda constitucional (n. 72 de 2005) que ela passaria antes pela Comissão de Constituição e Justiça (PEREIRA, POWER e RENNÓ, 2008: 7). Ou seja, mesmo com prerrogativa do Executivo, o Legislativo teria seu poder de veto, nesse caso, por meio da Comissão de Justiça.

As comissões, com esses propósitos, podem ser consideradas inovações institucionais trazidas pela Constituição de 1988. Embora menções às comissões possam ser encontradas nas Cartas de 1934 e 1946, é só o texto de 1967 que pode ser avaliado como um precursor da ideia de uma comissão com poder decisório no Brasil. Os trechos da Constituição Federal de 1967 expõem como o assunto foi introduzido naquele período:

$\mathrm{Na}$ constituição das Comissões, assegurar-se-á, tanto quanto possível, a representação proporcional dos Partidos nacionais que participem da respectiva Câmara. (BRASIL, 1967, parágrafo único, art. 32, Seção I, Capítulo VI).

[...] § $2^{\circ}$ - O projeto de lei, que receber parecer contrário quanto ao mérito, de todas as Comissões, será tido como rejeitado. (BRASIL, 1967, art. 61, Seção V, Capítulo VI). 
Mariele Troiano

[...] $\S 2^{\circ}$ - Os projetos de lei referidos neste artigo somente sofrerão emendas nas comissões do Poder Legislativo. Será final 0 pronunciamento das Comissões sobre emendas, salvo se um terço dos membros da Câmara respectiva pedir ao seu Presidente a votação em Plenário, sem discussão, de emenda aprovada ou rejeitada nas Comissões. (BRASIL, 1967, art. 67; Seção VI, Capítulo $\mathrm{VI})$.

A ideia do trabalho descentralizado em comissões também foi influência de textos constitucionais de outros países, utilizados durante a elaboração da atual Carta. O trecho da Constituição da Itália de 1947, por exemplo, mostra as semelhanças entre o funcionamento das comissões:

Cada projeto de lei, apresentado/submetido a uma Câmara é, segundo as normas de seu regulamento, examinado por uma comissão e depois pela mesma Câmara, que aprova artigo por artigo e com votação final [...]. Pode também estabelecer em quais casos e formas o exame e a aprovação dos projetos de lei são deferidos às comissões, também permanentes, compostas de modo a respeitar/refletir a proporção dos grupos parlamentares. (ITÁLIA, 1947, art. 72).

A Constituição Federal de 1988 define a composição das comissões e atribui a elas quatro específicas funções: discutir e votar projeto de lei, receber proposições de representantes de entidades civis, promover audiências públicas e solicitar depoimento de qualquer cidadão ou autoridade. A partir dessas características, pode-se concluir que poder e autonomia são atribuídos ao Legislativo por meio dos trabalhos em comissões:

Art. 58. O Congresso Nacional e suas Casas terão comissões permanentes e temporárias, constituídas na forma e com as atribuições previstas no respectivo regimento ou no ato de que resultar sua criação.

$\S 1^{0} \mathrm{Na}$ constituição das Mesas e de cada Comissão, é assegurada, tanto quanto possível, a representação proporcional dos partidos ou dos blocos parlamentares que participam da respectiva Casa.

$\S 2^{\circ}$ Às comissões, em razão da matéria de sua competência, cabe:

I - discutir e votar projeto de lei que dispensar, na forma do regimento, a competência do Plenário, salvo se houver recurso de um décimo dos membros da Casa;

II - realizar audiências públicas com entidades da sociedade civil;

[...]

IV - receber petições, reclamações, representações ou queixas de qualquer pessoa contra atos ou omissões das autoridades ou entidades públicas;

V - solicitar depoimento de qualquer autoridade ou cidadão; [...]. 
Mariele Troiano

(BRASIL, 1988, Seção VII das Comissões).

As funções das comissões, após a Constituição Federal, foram asseguradas pelos respectivos regimentos da Câmara dos Deputados (CD) e do Senado Federal (SF), reforçando a função de discutir e votar projetos de lei que dispensam a competência do plenário, salvo em casos de recursos de um décimo dos membros da Casa ou quando se referir a um projeto de natureza em que essa atuação seja vedada ${ }^{4}$. Cabe ressaltar que a quantidade de comissões permanentes e suas nomenclaturas podem variar conforme as legislaturas.

Além das comissões permanentes que possuem caráter técnico-legislativo, e têm por finalidade deliberar sobre determinado assunto, existem também as comissões temporárias, que surgem para a discussão de um tema específico e podem ser dissolvidas quando há a resolução da questão ou o término da legislatura. As Comissões Temporárias podem ser: especiais, internas ou parlamentares de inquérito (CPI). Há, ainda, as comissões mistas permanentes, como a Comissão Mista de Planos, Orçamentos Públicos e Fiscalização, composta tanto por deputados quanto por senadores, e as comissões mistas temporárias.

O estudo de comissões do legislativo brasileiro foi amplamente influenciado pela literatura neoinstitucionalista, fundamentada nas análises da House norte-americana. Essas abordagens partem da noção de que os indivíduos são maximizadores de seus interesses (OLSON, 1999), estando dentre os principais objetivos dos parlamentares a garantia da manutenção do poder. As diferenças entre as decisões seriam reflexos do arranjo das instituições e das preferências dos atores (ROCHA e BARBOSA, 2008).

Fernando Limongi (1994) foi pioneiro em analisar o Legislativo brasileiro via modelos da literatura americana que objetivam a existência das comissões. São eles os modelos distributivo, informacional e partidário.

O trabalho de Shepsle e Weingast (1987) é um clássico da abordagem distributivista, em que o processo legislativo é marcado pela constante negociação de benefícios políticos. Trata-se de uma relação de conflito na qual cada legislador tenta obter o máximo de privilégios às custas dos interesses de outros parlamentares, processo esse chamado por Rocha e Barbosa (2008) de "mercado de votos entre os parlamentares".

Para a abordagem informacional, o trabalho de Krehbiel (1991) é referência por apresentar os postulados da incerteza, da expertise e da majoritariedade. Segundo Krehbiel (1991), quando se trata de indivíduos e interesses, a concordância entre os envolvidos é a redução da incerteza e dos possíveis riscos. Dessa forma, as comissões seriam espaços de tomadas de decisões com base no maior volume possível de informações que sustentem um resultado. Essas informações seriam alimentadas por expertises, funcionando também como critério de distribuição dos parlamentares entre as comissões. Nesse caso, é a expertise que determina a preferência partidária, e não o contrário. 0 postulado majoritário reflete a quantidade de ideias envolvidas para que uma decisão seja tomada, sustentando os princípios da democracia e da soberania popular.

Cox e Mccubbins (1993) apresentam a abordagem partidária, sendo o espaço das comissões um governo partidário, ou seja, eles evidenciam os interesses dos indivíduos como exclusivamente partidários. As lideranças partidárias são os atores centrais nesse processo, responsáveis pela elaboração da agenda do partido e pela busca da constante coesão na arena legislativa.

De modo geral, os dois primeiros tendem a dar maior ênfase na autonomia das comissões, sendo o destaque do primeiro o caráter técnico, e o enfoque do segundo o 
Mariele Troiano

propósito da reeleição. Já o terceiro modelo compete à definição partidária e à materialização dos poderes dos líderes. Entretanto, os modelos não são excludentes nem exclusivos e são dependentes do relacionamento entre os poderes Executivo e Legislativo (ROCHA e BARBOSA, 2008).

A coexistência de características dos modelos distributivista, informacional e partidário pode ser evidenciada, de modo geral, nas comissões da Constituinte. Os parlamentares constituintes, por manterem seus trabalhos de parlamentares após a formulação da Constituição, estavam, de certo modo, preocupados com a distribuição entre seus representantes, ou seja, com os repasses entre seus pares, a manutenção do poder e o surgimento das alianças. A posteriori, o sistema eleitoral de listas abertas tornou ainda mais favorável a proximidade entre os parlamentares e seus representantes, o que embasaria a abordagem distributivista.

A questão partidária também foi predominante durante o processo constituinte e ganhou destaque com as funções de relatoria e presidência dentro das Comissões. Os relatores foram os responsáveis pela formulação do texto final de cada comissão sem necessidade de votação para aprovação. Além dos relatores, a Comissão de Sistematização seria composta por todos os presidentes de cada comissão e subcomissão.

Coelho (1999) destaca a importância do líder do PMDB, o constituinte Mário Covas, para a escolha dos parlamentares "mais progressistas" de seu partido para as vagas de relatorias e de presidências de todas as comissões e subcomissões, ocupando a Comissão de Sistematização (JOBIM, 1994; SOUZA, 2001). Para esse uso estratégico da composição partidária, o PMDB ocupou outros importantes cargos no processo, com Ulysses Guimarães na presidência da ANC e o senador Fernando Henrique Cardoso como relator do Regimento Interno, além de Bernardo Cabral como relator-geral da Constituinte. O gráfico a seguir exibe a predominância do PMDB na ocupação da Comissão de Sistematização.

\section{Gráfico 1: Representação partidária na Comissão de Sistematização}

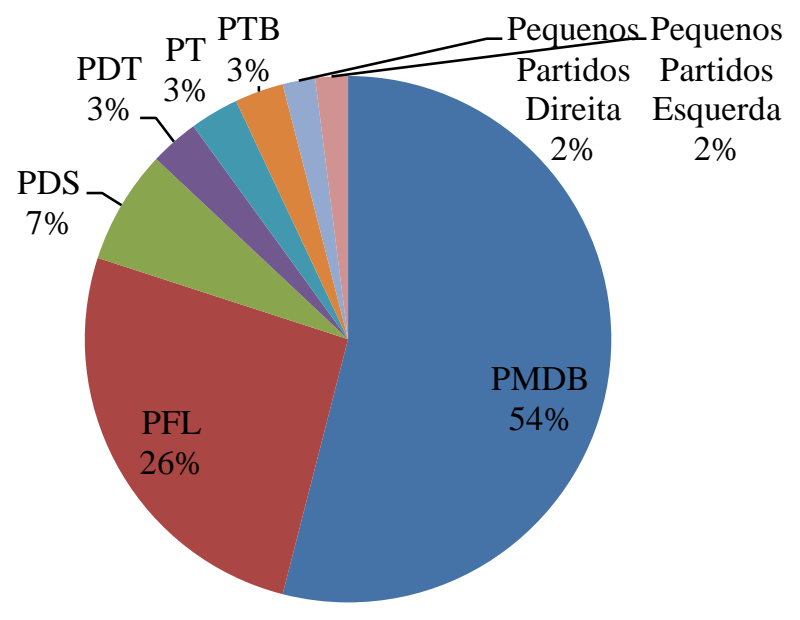

*Pequenos partidos de direita: PL, PDC, PMB.

**Pequenos partidos de esquerda: PSB, PCdoB, PCB.

Fonte: Freitas, Moura e Medeiros (2009: 14). 
Mariele Troiano

As comissões do Legislativo possuem as prerrogativas de tramitação urgente, prioritária ou ordinária, podendo trancar pauta e encaminhar o projeto de lei para a Ordem do Dia. Entretanto, quem possui o poder dessas iniciativas dentro das comissões são os líderes partidários. No quadro a seguir, é possível perceber que entre as maneiras de seleção dos atores legislativos para a composição dos cargos da CD, os líderes partidários estão envolvidos em muitas atuações de caráter exclusivo. Abaixo, estão algumas funções dos membros dentro da Comissão e formas de seleção:

Quadro 1: Funções e formas de seleção dos atores legislativos na Câmara dos Deputados

\begin{tabular}{|c|c|c|}
\hline Cargo/Órgão & $\begin{array}{l}\text { Forma de } \\
\text { Seleção }\end{array}$ & Poder de Seleção \\
\hline $\begin{array}{l}\text { Liderança de } \\
\text { partido e de } \\
\text { bloco (Art. } 9^{\circ}, 12 \\
\text { e } 13 \text { ) }\end{array}$ & Indicação & Maioria da bancada \\
\hline $\begin{array}{l}\text { Presidência de } \\
\text { Comissão } \\
\text { Permanente e } \\
\text { Temporária (Art. } \\
70,39 \text { ) }\end{array}$ & Eleição & $\begin{array}{l}\text { Maioria dos } \\
\text { membros titulares }\end{array}$ \\
\hline $\begin{array}{l}\text { Liderança e vice- } \\
\text { liderança do } \\
\text { governo (Art. 11) }\end{array}$ & Indicação & $\begin{array}{l}\text { Presidente da } \\
\text { República }\end{array}$ \\
\hline $\begin{array}{l}\text { Relatoria (Art. } \\
41 \text { ) }\end{array}$ & Designação & $\begin{array}{l}\text { Presidente da } \\
\text { Comissão }\end{array}$ \\
\hline $\begin{array}{l}\text { Comissão } \\
\text { Permanente (Art. } \\
10,28)\end{array}$ & Indicação & Líder \\
\hline $\begin{array}{l}\text { Comissão } \\
\text { Temporária } \\
\text { (Especial, } \\
\text { Externa e } \\
\text { Parlamentar de } \\
\text { Inquérito) (Art. } \\
\text { 34, 35, } 38 \text { e 45) }\end{array}$ & Indicação & Líder \\
\hline $\begin{array}{l}\text { Vice-liderança de } \\
\text { partido ou de } \\
\left.\text { bloco (Art. } 9^{\circ}\right)\end{array}$ & Indicação & Líder \\
\hline
\end{tabular}

Fonte: Brasil (1989) apud Miranda (2008).

Se a relação entre a quantidade de prerrogativas e a importância do líder partidário é perceptível nas comissões, é válido ressaltar que o Colégio de Líderes também surgiu enquanto prática durante o processo constituinte (de modo informal, pois não constava no Regimento Interno da ANC).

O constituinte Nelson Jobim (1994) relata que o Colégio de Líderes surgiu de forma indispensável na ANC, em uma fase em que era preciso a formação de consenso para o cumprimento dos prazos. O autor menciona que a maioria parlamentar, embora difícil entre os líderes, foi a solução encontrada diante da dificuldade de concordância entre as 
Mariele Troiano

demandas de grupos organizados. O trecho a seguir explicita como a concepção do Colégio de Líderes se estabeleceu na ANC.

\begin{abstract}
Então lançamos mão de um procedimento que eu havia copiado das Cortes Portuguesas, que eram as emendas de transação. Na hora da votação em plenário, se uma matéria não servia, criávamos um texto novo, fora do processo regimental. Esse texto novo era que formava a maioria, e então votávamos. Quando chegamos a 88 , após a promulgação da Constituição, criou-se o problema da existência de um órgão informal e imensamente poderoso - o Colégio de Líderes - e não havia espaço para destruí-lo. E nesse regimento que nós elaboramos (eu e os deputados Genoíno, Miro Teixeira, José Bonifácio, Israel Pinheiro, Paes Landim), institucionalizamos o Colégio de Líderes para definir seus poderes, porque se nós deixássemos informal, ele teria poderes absolutos. Se nós formalizássemos, ele teria os poderes que o regimento the desse. (JOBIM, 1994: 45).
\end{abstract}

O funcionamento do Colégio de Líderes foi assegurado na Constituição e mantido nas atividades rotineiras do Congresso Nacional, a priori, para auxiliar a Mesa Diretora em relação ao calendário de votações da Câmara dos Deputados (SANTOS, 2001).

Cabe mencionar que, na Câmara dos Deputados, um partido tem liderança quando a sua representação é igual ou superior a um centésimo da composição da Casa, ou seja, quando é igual ou superior a cinco deputados. Os partidos com bancada inferior podem indicar um representante para expressar a posição do partido.

As prerrogativas dos líderes parlamentares não se resumem à urgência da votação das proposições nas comissões ${ }^{5}$. As iniciativas dos líderes também estão previstas para a apresentação de emendas em plenário, as quais são aceitas se contarem com a assinatura de, pelo menos, um décimo da composição da Câmara ou dos líderes cujas bancadas representarem esse número (SANTOS, 2001).

Os líderes partidários são os responsáveis também pela indicação da composição das comissões permanentes. Nomear os membros das comissões é função importante devido ao poder terminativo que estas possuem, principalmente quando se referem à "Comissão de Constituição e Justiça e de Cidadania", onde todas as propostas de lei são submetidas, e à "Comissão de Finanças e Tributação", onde toda lei que trata de uso de recursos da União deve ser avaliada.

A Comissão de Constituição e Justiça e de Cidadania representa uma fase obrigatória de tramitação de projetos legislativos e, por isso, detém um importante poder formal de veto, ou o que Tsebelis (1997) chamou de veto player institucional. Conforme Ribeiral (1998: 75), essa Comissão expõe não só a alta produtividade, como também pouca interferência de pedidos de urgência, significando um alto grau de autonomia decisória das comissões.

Assinala-se, ainda, que a composição proporcional das comissões por parte dos partidos forneceria um arcabouço plural de informações para a formação de consenso e deliberação legislativa, possibilitando a formação de especialistas. Embora seja possível analisar a abordagem informacional nos trabalhos das comissões, ela fica ainda mais enfatizada diante das audiências públicas que aconteciam em seus interiores.

Fato é que a maioria das decisões do Legislativo ocorrem nas comissões e são precedidas por audiências públicas (MIRANDA, 2012). Assim, as audiências públicas são etapas esperadas dentro do processo e compreendidas como ferramentas de articulação de 
Mariele Troiano

recursos para a decisão. Esse funcionamento já havia sido proposto como parte do fortalecimento do Legislativo e do projeto democrático.

\section{Permeabilidade social por meio das audiências públicas}

Os estudos sobre a participação dos setores da sociedade civil em processos decisórios tendem a ser numerosos quando tratam dos conselhos, do orçamento participativo e das conferências (SOUZA, 2013; AVRITZER, 2012; POGREBINSCHI, 2013). Mas pouca atenção tem sido dada ao espaço das audiências públicas como lócus de produção de lei. A literatura internacional justifica a ausência de estudos sobre elas por representarem a mais inefetiva entre as técnicas de participação pública (KING, FELTEY e SUSEL, 1998: 323). A ineficiência pode ser sustentada pela ideia de que, muitas vezes, uma audiência pública é requerida sem serem mencionados os reais motivos da discussão (BURBY, 2003: 36).

A escassez de estudos sobre essas audiências reflete também a ausência de uma definição desse espaço na literatura especializada. Trabalhos do campo jurídico as entendem como instrumentos auxiliares no julgamento e na promoção do diálogo entre a autoridade e a sociedade, seja esta última por fazer parte do caso, seja por ser uma expertise na área (GOMES et al., 2014). No campo administrativo, as audiências aparecem como as responsáveis por integrar representantes e representados, podendo ser entidades da sociedade civil ou segmentos específicos da sociedade (SOARES, 2002).

Saule Jr. (2014: 17) é quem traz a arena legislativa para a definição de audiências públicas ao afirmar que elas são "garantias processuais dos direitos coletivos e difusos, tanto pelo Poder Executivo quanto pelo Poder Legislativo, sendo, portanto, um componente essencial tanto do processo administrativo como do processo legislativo". Já Oliveira (1997: 276) vai mais além e afirma que a participação de atores externos está "formalmente disciplinada em lei, pela qual se exerce o direito de expor tendências, preferências e opções que possam conduzir o Poder Público a uma decisão de maior aceitação consensual".

Dessa forma, a definição de uma audiência pública tende a circular entre suas funções consultiva, informativa e coletiva; enquanto outras características poderiam ser ressaltadas. $\mathrm{O}$ fato de as audiências públicas serem permanentes, presenciais, com manifestação oral dos envolvidos e totalmente documentadas em notas taquigráficas, as faz diferentes de outras arenas participativas. Além disso, devem ser consideradas as regras regimentais para o seu funcionamento, como procedimentos formais de data e hora definidas, pauta, justificativa de cancelamento, confecção de atas de reunião e gravação de áudio dos debates (SOARES, 2002; MATTOS, 2004).

Há também regras relacionadas à condução do debate pelo deputado que preside a comissão, formaliza a ordem dos atores que têm a palavra, apresenta os autores do requerimento da audiência e delimita o tempo de fala de cada participante, bem como das possíveis réplicas e tréplicas (FONSECA et al., 2013: 11). Portanto, as audiências como espaços de intermediação implicam na existência prévia de regras que regem as opiniões e demandas dos atores externos dentro da arena legislativa. Somadas a essas características, deve-se mencionar duas especificidades das audiências públicas das comissões permanentes da Câmara dos Deputados: primeiro por antecederem o poder de decisão em plenário e, segundo, pelos representantes da sociedade poderem ser convidados diretos do parlamentar que requer a audiência, que relata ou que preside uma comissão.

A audiência pública é um mecanismo institucional colocado à disposição dos órgãos públicos para promover um diálogo com os atores da sociedade. Elas podem ser requeridas 
por qualquer deputado membro de Comissão ou entidade interessada. A realização de reunião de audiência pública depende de aprovação pela maioria simples da comissão, e seu objetivo deve ser instruir matéria legislativa em trâmite ou debater assuntos de interesse público relevantes, referentes à área de atuação da Comissão. Assim, elas têm como objetivo qualificar o debate ou a deliberação, trazendo informação das preferências dos diferentes grupos sociais (BRASIL, 2016).

As audiências podem servir como instrumentos para coleta de conhecimento técnico, provas, depoimentos, opiniões, documentos e dados, ou seja, elas têm como princípio a circulação de informação. Nessa ocasião, pode-se considerar que com as audiências públicas o processo decisório atinge seu grau máximo de permeabilidade institucional, na medida em que insere um ator externo convidado na arena de tomada de decisão.

O quadro a seguir apresenta um conjunto de características como proposta de uma definição completa das audiências públicas.

\section{Quadro 2: Principais características das audiências públicas das Comissões Permanentes da Câmara dos Deputados}

\begin{tabular}{|c|c|}
\hline \multirow{11}{*}{$\begin{array}{l}\text { O que } \\
\text { define } \\
\text { uma } \\
\text { audiência } \\
\text { pública? }\end{array}$} & 1) Caráter Consultivo \\
\hline & 2) Caráter Informativo \\
\hline & 3) Caráter Coletivo \\
\hline & 4) Caráter Presencial \\
\hline & 5) Caráter Público (aberta a todos os interessados) \\
\hline & 6) Manifestação oral dos participantes \\
\hline & 7) Documentada em atas e notas taquigráficas \\
\hline & 8) Implica constante debate entre os atores \\
\hline & 9) Contém regras específicas para seu acontecimento \\
\hline & 10) Caráter que antecede à deliberação de uma proposição \\
\hline & $\begin{array}{l}\text { 11) Caráter Político (atores externos convidados pelos } \\
\text { parlamentares) }\end{array}$ \\
\hline
\end{tabular}

Fonte: Adaptado de Fonseca et al. (2013: 11).

As audiências públicas, como forma de consulta pública, remetem às public hearings do Reino Unido, sendo seu primeiro registro datado de 1403, em Londres, permanecendo essenciais para as decisões da monarquia até os dias atuais (SÁNCHEZ, 2008).

No Brasil, elas são resultantes do processo constituinte. Aliás, foram institucionalizadas no âmbito do Governo Federal com o conjunto de processos participativos previstos pela Constituição de 1988 (PIRES e VAZ, 2010).

Foi a segunda resolução do Regimento Interno da Assembleia Nacional Constituinte, aprovada em 19 de março de 1987, que determinou a realização das audiências públicas nas subcomissões, com o propósito de permitir a atuação direta da sociedade civil (art. 14). Na mesma resolução, estavam outras medidas que possibilitaram maior participação da sociedade civil, tais como o recebimento de sugestões de órgãos legislativos subnacionais, de entidades associativas, de tribunais e de parlamentares (art. 13), além da apreciação de emendas populares com 30 mil assinaturas (art. 24).

A temática das audiências públicas entrou em debate na ANC com a emenda apresentada pelo constituinte Adhemar de Barros Filho, do Partido Democrático Trabalhista (PDT), garantindo que as comissões realizassem sessões de audiência à sociedade civil 
Mariele Troiano

organizada, assegurando lugar e direito de pronunciamento aos representantes das entidades constituídas em caráter nacional. A justificativa para a emenda dada pelo parlamentar era de que a temática resgatava uma das mais importantes bandeiras do seu partido político, que procurava viabilizar as demandas dos setores da sociedade expressadas por organizações como União Nacional dos Estudantes (UNE), Ordem dos Advogados do Brasil (OAB), Conferência Nacional dos Bispos do Brasil (CNBB), sindicatos, Federações e Confederações patronais e de trabalhadores (BACKES, AZEVEDO e ARAÚJO, 2009: 23). Assim, cabe ressaltar que os espaços criados na Constituinte também devem ser compreendidos como eixos de luta conquistados pela sociedade civil ou, ainda, como colocado por Brandão (2011), representam oportunidades de mobilização social que foram institucionalizadas dentro da ANC.

Nos discursos dos constituintes, é possível interpretar que a existência das audiências públicas seria uma ferramenta para assegurar a participação de atores externos nos trabalhos da ANC e enriquecer os debates com os dados técnicos e preocupações recorrentes. A seguir, o discurso do constituinte Octávio Elísio ilustra o explicitado:

\begin{abstract}
Quando nós decidimos, como constituintes, por esse espaço de audiência pública, havia uma determinação de que não era possível fazer uma nova Constituição sem se ouvir a sociedade, sem deixar claro, em termos de um dispositivo regimental, que a verdadeira Constituinte acontece fora do prédio do Congresso, e que esta Assembleia Nacional Constituinte, que, aqui e agora, se reúne em Subcomissões, não vai responder aos anseios da sociedade se não ouvir essa sociedade. (Constituinte Octávio Elísio, Diário da ANC- Suplemento, 16/7/1987: 190).
\end{abstract}

A segunda resolução do Regimento Interno definiu também que as subcomissões durante a Constituinte teriam de cinco a oito audiências públicas, podendo, durante o prazo, receber sugestões encaminhadas à Mesa ou à comissão em questão. A prática das audiências públicas na ANC iniciou-se em 22 de abril de 1987, ocupando as agendas de todas as subcomissões. Conforme Backes, Azevedo e Araújo (2009: 15), foram mais de 200 audiências públicas nessa fase do processo constituinte, que contou com a participação de quase 900 pessoas, sendo a distribuição nas comissões a seguinte: 
Mariele Troiano

\section{Gráfico 2: Distribuição de audiências públicas durante o processo constituinte de 1987-88}

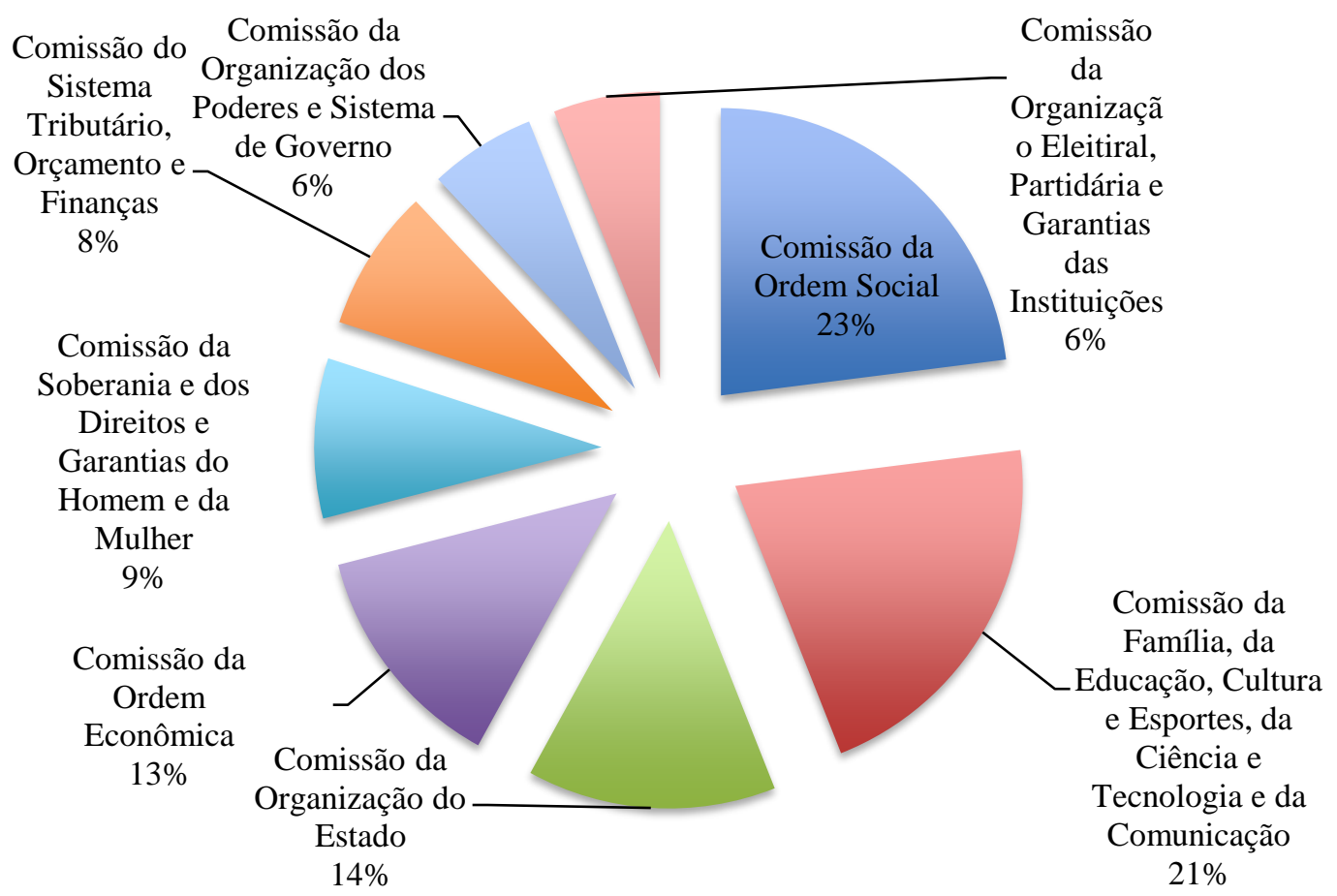

Fontes: Backes, Azevedo e Araújo (2009).

A permeabilidade à sociedade na arena decisória é necessária, mas não suficiente para o funcionamento pleno da democracia, ou seja, mais que ouvir a sociedade, o Legislativo tem de ser capaz de decidir em nome dela. Necessariamente, isso implica em produção e circulação de informação. Embora abordagens distributivistas ressaltem que os parlamentares visam à reeleição (SHEPSLE e WEINGAST, 1987), em alguma medida, o feito é consequência de os atores tornarem-se capazes de clamar créditos pela produção de políticas positivas e evitarem culpa por políticas negativas (MAYHEW, 2004). É dentro das audiências públicas que a abordagem informacional das comissões ganha espaço.

É o uso estratégico da informação e o grau de incerteza que, segundo Krehbiel (1991), leva à organização do Legislativo em comissões. Mais que abrigar parlamentares de polos opostos do espectro ideológico, as comissões heterogêneas operacionalizam o processo decisório sobre uma base informacional plural. Para a teoria informacional, o plenário concede certos poderes às comissões, como incentivo para que se especializem, adquiram informação e passem-na para o plenário (GILLIGAN e KREHBIEL, 1987;

KREHBIEL, 1991). Com isso, mais do que produzir políticas direcionadas aos seus eleitores, os parlamentares se preocupariam em produzir boas políticas, pois são elas que garantiriam a reeleição. Dessa forma, uma das principais características das audiências públicas é produzir informação que auxilie nesse processo.

Com essa explanação sobre as transformações estruturais iniciadas durante o processo constituinte, as audiências públicas foram apresentadas como um espaço utilizado com o propósito maior de participação, inclusão e envolvimento dos atores externos, bem como parte de um projeto institucional em prol de um Legislativo mais ágil e eficiente. Com isso, a produção de consenso via conflitos de interesses nessa arena ofereceria respaldos informacionais às decisões políticas, sejam elas tomadas por parlamentares presidentes, requerentes, relatores, autores ou líderes partidários. 
Mariele Troiano

Arranjos teóricos que explicam processos decisórios aproximam a abordagem informacional da tomada de decisão mais favorável ao maior número de atores envolvidos, conferindo caráter estratégico à informação. Ou seja, as audiências públicas podem diminuir incertezas, trazendo informação relevante para a tomada de decisão e, consequentemente, influenciando a qualidade das políticas públicas.

As audiências públicas somadas às comissões foram inovações do processo constituinte, visando maior eficiência do processo legislativo e fortalecimento do desenho democrático. Assim, se de um lado o Executivo ganhou prerrogativas em suas funções legislativas, após a Constituição de 1988, este artigo aponta para o fortalecimento do Legislativo por meio de comissões permanentes e audiências públicas, seus poderes terminativos e intersecções com a sociedade.

\section{Considerações Finais}

A Constituição atual nasceu da incapacidade do antigo regime político de responder às novas demandas refletidas nos problemas econômicos, sociais e políticos. Os constituintes representaram a necessidade da construção de um novo consenso contingente, resultante de uma negação do passado recente, uma resposta ao presente e uma proposta de projeto a ser seguido. Esse elo entre recusa do efeito negativo de um período anterior e um novo pacto para o presente/futuro é o momento de inflexão que legitima o processo decisório e delimita a Constituição como mantenedora da democracia.

A mobilização em torno da construção de um novo pacto social coincide com o surgimento de novos atores políticos, demandas sociais, surgimento da noção de espaço público e do paradigma de cidadania. A estrutura do processo constituinte refletia esse quadro de demandas ao assegurar a participação de todos na elaboração da Carta constitucional, por meio de formas institucionais, bem como da apresentação de sugestões oriundas de entidades representativas de segmentos da sociedade, audiências públicas e emendas populares. A particularidade de abertura do processo decisório possibilitou à Constituinte uma prática inédita de formulação constitucional.

As respostas às demandas sociais, a formação do paradigma de cidadania, a multiplicação de atores e de interesses servem também de justificativa à produção de um texto constitucional considerado programático.

A atuação do Legislativo é, por definição, um permanente processo de deliberação. A Constituição de 1988 adotou o poder de apreciação conclusiva das comissões (também chamado de poder terminativo), que permite que estas discutam e votem projetos de lei, dispensando a competência do Plenário.

Alguns avanços podem ajudar nessa consolidação de um Legislativo mais amplo e menos controlado pelo Executivo. Ou seja, há necessidade, ainda, de estudos sobre o funcionamento da indicação dos membros, presidentes e relatores e quais são os espaços possíveis para as minorias parlamentares acessarem esse espaço de representação, garantindo a diversidade.

Fato é que a Constituição foi conclusão de um longo processo de democratização no nosso país, envolvendo vários atores, conflitos e decisões. Analisar o Executivo sem se dar conta das mudanças que o Legislativo promoveu é concluir erroneamente que não tivemos uma ruptura institucional e, consequentemente, não atribuir o funcionamento previsto dos poderes da República como parte de um projeto democrático. A partir do momento em que há a compreensão de que a engenharia institucional atualmente estabelecida é parte de um todo, que há necessidade de uma inteligência coletiva para resolver problemas complexos 
da nossa sociedade e que política não envolve só questões financeiras, mas também a esfera pública, sendo obrigatoriamente resoluta de questões sociais, a democracia estará mais próxima de sua consolidação. Esse é o projeto democrático brasileiro, e a Constituição é o ethos da sua execução.

(Recebido para publicação em setembro de 2020)

(Reapresentado em setembro de 2020)

(Aprovado para publicação em dezembro de 2020)

\section{Cite este artigo}

TROIANO, Mariele, 2020. As audiências públicas no processo constituinte de 1987-88. Revista Estudos Políticos: a publicação semestral do Laboratório de Estudos Hum(e)anos (UFF). Rio de Janeiro, Vol.11 | N.22, pp. 108-130, dezembro de 2020.

\section{NOTAS}

1. Segundo Bolívar Lamounier (apud DINIZ e PRAÇA, 2008, p. 21), essa designação, "comissão dos notáveis", era pejorativa, utilizada por parte dos adversários e da imprensa.

2. O jurista Afonso Arinos havia participado do processo constituinte anterior. Com a queda do Estado Novo em outubro de 1945, concorreu por Minas Gerais, em dezembro, às eleições para a Assembleia Nacional Constituinte e obteve uma suplência.

3. O debate sobre os senadores remanescentes do Regime Militar, bem como outras questões militares foram abafados na Constituinte. A utilização do termo "gag rules" ou "as leis da mordaça" apresentado por Holmes (1993) aplica-se a essa questão.

4. Os casos em que essa atuação decisória das comissões é vedada são: quando se tratar de um projeto de lei complementar, de um código, de uma iniciativa popular; de uma proposta de uma comissão; relativos à matéria que não possa ser objeto de delegação; oriundos do Senado, ou por ele emendados, que tenham sido aprovados pelo plenário de qualquer das Casas; que tenham recebido pareceres divergentes ou que tramitam em regime de urgência, conforme artigo 132 do Regimento Interno.

5. O pedido de urgência é encaminhado à Mesa Diretora de cada Casa pelo Colégio de Líderes, e a assinatura de cada líder é ponderada pelo tamanho da bancada sob seu comando. A votação deve ocorrer no máximo 
Mariele Troiano

em 45 dias, podendo substituir as votações em plenário.

\section{Referências Bibliográficas}

AMES, Barry. Electoral Rules, Constituency Pressure, and Pork Barrel: Bases of Voting in the Brazilian Congress.

Journal of Politics, v. 57, n. 2, p. 324-343, 1995.

ARROW, Kenneth. Social choice and individual values. New Haven: Yale University Press, 1963.

AVRITZER, Leonardo. Conferências nacionais: ampliando e redefinindo os padrões de participação social no Brasil. Rio de Janeiro: Ipea, 2012. (Texto para Discussão, n. 1739.)

BACKES, Ana Luiza; AZEVEDO, Débora Bithiah; ARAúJO, José Cordeiro de (Orgs.). Audiências públicas na Assembleia Nacional Constituinte: a sociedade na tribuna. Brasília, DF: Edições Câmara, 2009.

BRASIL. Constituição da República dos Estados Unidos do Brasil. Rio de Janeiro, 1934. Disponível em:

<http://www.planalto.gov.br/ccivil_03/Constituicao/Constit uicao34.htm>. Acesso em: 24 out. 2014.

BRASIL. Constituição dos Estados Unidos do Brasil. Rio de Janeiro, 1946. Disponível em:

<http://www.planalto.gov.br/ccivil_03/Constituicao/Constit uicao46.htm>. Acesso em: 24 out. 2014.

BRASIL. Constituição da República Federativa do Brasil. Brasília, 1967. Disponível em:

<http://www.planalto.gov.br/ccivil_03/Constituicao/Constit uicao67.htm>. Acesso em: 24 out. 2014.

BRASIL. Constituição Federal de 1988. Disponível em: <http://www.planalto.gov.br/ccivil_03/constituicao/constit uicaocompilado.htm>. Acesso em: 22 set. 2016.

BRASIL. Câmara dos Deputados. Resolução n. 17, de 1989: Regimento Interno da Câmara dos Deputados. 17a ed. Brasília, 2016a. Disponível em:

<http://www2.camara.leg.br/documentos-epesquisa/edicoes/paginas-individuais-dos-livros/regimentointerno-da-camara-dos-deputados-1> Acesso em 22 set. 2016.

BRASIL. Câmara dos Deputados. 2016 a. Discursos e Notas Taquigráficas. Disponível em:

<http://www2.camara.leg.br/deputados/discursos-enotas-taquigraficas> Acesso em 2 out. 2016.

BRASIL. Câmara dos Deputados. 2016 b. Histórico e Atribuições - Comissões. Disponível em: $<$ http://www2.camara.leg.br/atividade- 
Mariele Troiano

legislativa/comissoes/comissoes-

permanentes/cmads/conheca-a-comissao/index.html> Acesso em 1 out. 2016.

BEHNKE, Emilly; SAMPAIO, Dida. "Democracia e Liberdade acima de tudo", diz Bolsonaro um dia após participar de ato pró-ditadura. O Estado de São Paulo. https://politica.estadao.com.br/noticias/geral,democraciae-liberdade-acima-de-tudo-diz-bolsonaro-um-dia-depoisde-ir-a-ato-pro-ditadura,70003276957 São Paulo. 20 de abril de 2020.

BONAVIDES, Paulo. A evolução constitucional do Brasil. Estudos Avançados, São Paulo, v.14, n.4, p.155-176, 2000.

BRANDÃO, Lucas C. Os movimentos sociais e a Assembleia Nacional Constituinte de 1987-1988: entre a política institucional e a participação popular. Dissertação de Mestrado. Universidade de São Paulo, São Paulo: 2011.

BURBY, Raymond. J. Making Plans that Matter: Citizen Involvement and Government Action. American Planning Association Journal, v. 69, n. 1, p. 33-49, 2003.

CHEIBUB, José. Antônio.; PRZEWORSKI, Adam.; SAIEGH, Sebastian. Governos de coalizão nas democracias presidencialistas e parlamentaristas. Dados, Rio de Janeiro, v. 45, n. 2, p. 187-218, 2002. Disponível em: <http://www.scielo.br/scielo.php?script=sci_arttext\&pid=S 0011-52582002000200001\&lng=en\&nrm=iso > . Acesso em: 23 jun. 2015.

COELHO, J. G. L. Processo constituinte, audiências públicas e o nascimento de uma nova ordem. In Backes, A. L.; Azevedo, D. B.; Araújo, J. C. (Orgs.), Audiências públicas na Assembleia Nacional Constituinte: a sociedade na tribuna. Brasília: Câmara dos Deputados, Edições Câmara, 2009.

COELHO, Ricardo C. Partidos políticos, maiorias parlamentares e tomada de decisão na Constituinte. 1999. Tese (Doutorado) - Departamento de Ciência Política da Universidade de São Paulo, São Paulo, 1999.

COX, G. W.; MCCUBBINS, M. D. Legislative Leviathan: Party Government in the House. Berkeley: University of California Press, 1993.

DINIZ, Simone; PRAÇA, Sérgio. Vinte anos da Constituição. Paulus: São Paulos, 2008.

FIGUEIREDO, Argelina. C.; LIMONGI, Fernando. Mudança constitucional, desempenho do Legislativo e consolidação institucional. Revista Brasileira de Ciências Sociais, São Paulo, v. 10, n. 29, p. 175-200, out. 1995. 
Mariele Troiano

FIGUEIREDO, Argelina. C.; LIMONGI, Fernando. Executivo e Legislativo na Nova Ordem Constitucional. Rio de Janeiro: Editora da FGV, 1999.

FONSECA, Igor et al. Audiências públicas: fatores que influenciam seu potencial de efetividade no âmbito do Poder Executivo Federal. Revista do Serviço Público, v. 64, n. 1, p. 7-29, jan./mar. 2013.

FREITAS, Rafael; MOURA, Samuel; MEDEIROS, Danilo. Procurando o Centrão: Direita e Esquerda na Assembleia Nacional Constituinte de 1987-88. Disponível em: <http://www.cebrap.org.br/v3/arquivos/artigos/procurand o-o-centrao-direita-e-esquerda-na-assembleia-nacionalconstituinte-1987-88-315.pdf> Acesso em: 29 set. 2016. In: M. A. R. De Carvalho, C. Araújo e J. A. Simões (Eds.) A Constituição de 1988: passado e futuro. São Paulo: Hucitec e ANPOCS, 2009. pp. 101-135.

GILLIGAN, Thomas; KREHBIEL, Keith. Collective decisionmaking and standing committees: an informational rationale for restrictive amendment procedures. Journal of Law, Economics, and Organization, 3: 287-335, 1987

GOMES, D. F. et al. Judicialização da saúde e a audiência pública convocada pelo Supremo Tribunal Federal em 2009: o que mudou de lá para cá? Saúde Debate, v. 38, n.100, p.139-156, 2014.

HOLMES, Stephen. Gag rules or the politics of omission. In: Elster, Jon (et al.). Constitutionalism and democracy. 1993.

ITÁLIA. Costituzione della repubblica italiana, 1947.

Disponível em:

<http://www.giurcost.org/fonti/cost_ital.html>. Acesso em: 10 jun. 2015.

JOBIM, Nelson. O desafio do Congresso Nacional: mudanças internas e consolidação institucional. Cadernos de Pesquisa, n. 3, p. 37- 59, 1994.

KREHBIEL, Keith. Information and Legislative Organization. Ann Arbor: University of Michigan Press, 1991.

KING, Cheryl. S.; FELTEY, Kathryn. M.; SUSEL Briget O. The Question of Participation: Toward Authentic Public Participation in Public Administration. Public Administration Review, v. 58, n. 4, p. 317-326, 1998.

LEMOS, Leany. B. S. O Congresso brasileiro e a distribuição de benefícios sociais no período 1988/1994: uma análise distributivista. Dados, Rio de Janeiro, v. 44, n. 3, p. 561-604, 2001. 
LEVITSKY, Steven; ZIBLATT, Daniel. How Democracies die. New York: Broadway Books, 2018.

LIMONGI, Fernando. O novo institucionalismo e os estudos legislativos: a literatura norte-americana recente. Boletim Informativo Bibliográfico, n. 37, p. 3-38, 1994.

LINZ, Juan. J. Presidential or Parliamentary Democracy: Does it Make a Diference? In: LINZ, J. J.; VALENZUELA, A. (Eds.). The Failure of Presidential Democracy: The Case of Latin America. Baltimore: The Johns Hopkins University Press, 1994. v. 2.

LOPES, Júlio. Aurélio. Vianna. A carta da democracia: 0 processo constituinte da ordem pública de 1988. Rio de Janeiro: Topbooks, 2008.

MATTOS, Paulo. Regulação econômica e social e participação pública no Brasil. In: CONGRESO INTERNACIONAL DEL CLAD SOBRE LA REFORMA DEL ESTADO Y DE LA ADMINISTRACIÓN PÚBLICA, 9, 2004, Madrid.

MIRANDA, Geralda. O comportamento dos partidos na Câmara dos Deputados e no Senado Federal (1991-2007). 2008. Tese (Doutorado em Ciência Política) - Universidade Federal de Minas Gerais, Belo Horizonte, 2008.

MÜLLER, Gustavo. Representação política: neoinstitucionalismo em perspectiva comparada. Revista Brasileira de Ciências Sociais [on-line], v. 24, n. 69, p. 115127, 2009.

NORONHA, Eduardo. Mudança institucional e a Constituinte de 1988: temas e preferências de empresários e sindicalistas. In: ENCONTRO DA ASSOCIAÇÃO BRASILEIRA DE CIÊNCIA POLÍTICA (ABCP), 7, 2010, Recife. Anais... Disponível em:

<http://cienciapolitica.servicos.ws/abcp2010/trabalhosite/v isualiza_popup1.asp?IdAtividade $=1104>$. Acesso em: 2 jan. 2012.

OLIVEIRA, Gustavo. H. As audiências públicas e o processo administrativo brasileiro, Revista de Direito Administrativo, Rio de Janeiro, v. 209, p. 153-167, jul./set. 1997.

OLSON, Mancur. A lógica da ação coletiva. São Paulo: Edusp, 1999.

PEREIRA, Chaisy; POWER, Timothy; RAILE, Eric D. Coalitional Presidentialism and Side Payments: Explaining The "Mensalão" Scandal in Brazil. Oxford: Brazilian Studies Programme, University of Oxford, 2008. (Paper.)

PEREIRA, Carlos; POWER, J. Timothy.; RENNÓ, Lúcio. Agenda Power, Executive Decree Authority, and the Mixed 
Results of Reform in the Brazilian Congress. Legislative Studies Quarterly, v. 33, n. 1, p. 5-33, 2008.

PILATTI, Adriano. A Constituinte de 1987-88: progressistas, conservadores, ordem econômica e regras do jogo. Rio de Janeiro: Lumen Juris/Editora PUC-Rio, 2008.

PIRES, Roberto; VAZ, Alexander. C. N. Participação faz diferença? Uma avaliação das características e efeitos da institucionalização da participação nos municípios brasileiros. In: AVRITZER, L. (Org.). A dinâmica da participação local no Brasil. São Paulo: Cortez, 2010.

POGREBINSCHI, Thamy. Conferências nacionais e políticas públicas para grupos minoritários. In: AVRITZER, L.; SOUZA, C. H. L. (Orgs.). Conferências nacionais: atores, dinâmicas participativas e efetividades. Brasília: Ipea, 2013.

REZENDE, Flávio da Cunha. Convergências e controvérsias sobre a mudança institucional: modelos tradicionais em perspectiva comparada. Rev. Sociol. Polit., Curitiba , v. 20, n. 41, p. 37-51, 2012. Disponível em <http://www.scielo.br/scielo.php?script=sci_arttext\&pid=S $010444782012000100004 \& \mathrm{lng}=\mathrm{en} \& \mathrm{nrm}=\mathrm{iso}>$. Acesso em 30 de junho de 2020.

RIBEIRAL, T. B. Comissão de Constituição e Justiça: uma ilha de institucionalização no Congresso Nacional. Revista do Legislativo, Belo Horizonte, 1998.

ROCHA, Marta Mendes.; BARBOSA, Cássio Ferreira. Regras, incentivos e comportamento: as comissões parlamentares nos países do Cone Sul. Revista de Sociologia e Política, Curitiba, v. 16, supl., p. 93-104, 2008.

RODRIGUES, Alberto Tosi. Ciclos de mobilização política e mudança institucional no Brasil. Revista de Sociologia e Política, Curitiba, n. 17, p. 33-43, nov. 2001. Disponível em:

<http://www.scielo.br/scielo.php?script=sci_arttext\&pid=S 0104-44782001000200004\&lng=en\&nrm=iso >. Acesso em: 21 jun. 2015.

SALLUM JR., Basílio. Labirintos: dos generais à Nova República. São Paulo: Hucitec, 1996.

SÁNCHEZ, Luis Enrique. Avaliação de impacto ambiental: conceitos e métodos. São Paulo: Oficina de Textos, 2008.

SANTOS, Fabiano. O Poder Legislativo nos estados: diversidade e convergência. Rio de Janeiro: FGV, 2001.

SAULE JR., Nelson. A participação dos cidadãos no controle da administração pública. [s.d.] Disponível em: 
<http://www.polis.org.br/uploads/840/840.pdf>. Acesso em: 10 maio 2014.

SHEPSLE, Kenneth. A.; WEINGAST, Barry. R. The Institutional Foundations of Committee Power. American Political Science Review, v. 81, p. 85-104, 1987.

SOARES, Evanna. A audiência pública no processo administrativo. Jus Navigandi, 2002. Disponível em: < http://jus.com.br/revista/texto/3145/a-audiencia-publicano-processo-administrativo/1>. Acesso em: 8 ago. 2011.

SOUZA, Celina. Federalismo, descentralização na Constituição de 1988: processo decisório, conflitos e alianças. Dados, Rio de Janeiro, v. 44, n. 3, p. 513- 560, 2001.

SHUGART, Mattew.; CAREY, John. (1992), Presidents and Assemblies: constitutional design and electoral dynamics. Cambridge, Cambridge University Press.

TSEBELIS, George. Processo decisório em sistemas políticos: veto players no presidencialismo, parlamentarismo, multicameralismo e pluripartidarismo. Revista Brasileira de Ciências Sociais, v. 12, n. 34, p. 89117, 1997.

WHITAKER, Francisco. et al. Cidadão constituinte: a saga das emendas populares. Rio de Janeiro: Paz e Terra, 1989. 